\title{
EFFECT OF PROBIOTIC CHEWABLE TABLETS ON ORAL HEALTH AND WHITE SPOT LESIONS IN PRE-SCHOOL CHILDREN: A RANDOMIZED CLINICAL TRIAL
}

\author{
Dalia A.M. Talaat*
}

\begin{abstract}
Objective: To evaluate the effect of chewable probiotic tablets on plaque accumulation and gingival inflammation, salivary $\mathrm{pH}$ and remineralization of white spot lesions in pre-school children with high caries risk.
\end{abstract}

Materials and Methods: A randomized clinical trial with two parallel arms was used with a sample of 40 high caries risk children 3-5 years old. Children were divided randomly into two equal groups. Group I: children received probiotic tablets and were instructed to chew it once daily after routine tooth brushing for two weeks. Group II: children performed only routine tooth brushing. A plaque and gingival indices were scored, salivary $\mathrm{pH}$ was assessed, and DIAGNOdent ${ }^{\mathrm{TM}}$ readings were recorded from all participants at baseline and after two weeks of intervention.

Results: Data showed that after two weeks of intervention, the mean plaque index after using the probiotic chewable tablets was lower than the control group with statistically significant difference. The mean gingival index was lower in the test group than the control group with statistically significant difference. Probiotic showed a percent increase in the mean $\mathrm{pH}$ values, while the control group showed a percent decrease at the end of the study with statistically significant difference between the two groups. Both groups showed a decrease in the mean DIAGNOdent ${ }^{\mathrm{TM}}$ scores with no statistically significant difference between them.

Conclusion: Probiotics play an important role in the improvement of oral health. Additionally, they can be used as an adjunct to fluoride in dental caries prevention or control in high caries risk children.

KEYWORDS: Probiotics, Plaque index, Gingival index, Salivary pH, White spot lesions

* Associate Professor of Pediatric Dentistry, Pediatric Dentistry and Dental Public Health Department, Faculty of Dentistry, Alexandria University, Egypt. 


\section{INTRODUCTION}

Dental caries is the most prevalent chronic disease in the world ${ }^{(1)}$. According to the American Academy of Pediatric Dentistry (AAPD), dental plaque on teeth, low salivary buffering capacity, low salivary fluoride level, and high counts of Streptococcus mutans (S. mutans) are risk factors for dental caries ${ }^{(2)}$. The usual treatment for caries used to be the operative approach of complete caries removal. However, modern dentistry is now focused upon prevention rather than treatment ${ }^{(3)}$. Children with white spot lesions (WSLs) should be considered as high risk for caries (4). Early detection of these non cavitated lesions helps to prevent progression of the disease ${ }^{(5)}$. Affecting microorganisms and control of dental plaque are important strategies to prevent dental caries process from occurring ${ }^{(6,7)}$. Traditional measures, tooth brushing and dental flossing, used to control dental plaque and decrease the count of caries associated bacteria in high caries risk individuals could be not highly effective ${ }^{(8)}$. Therefore, the concept of microbial ecological change as a mechanism for preventing dental caries is an important one such as bacteriotherapy or replacement therapy ${ }^{(7)}$. It combats infections by using harmless bacteria to replace the pathogenic microorganisms and the administration of probiotic bacteria being among the most common of its clinical applications ${ }^{(7)}$.

According to the Food and Agriculture Organization (FAO) and World Health Organization (WHO) ${ }^{(9)}$, probiotic bacteria are defined as living micro-organisms which, when administered in adequate amounts, confer a health benefit on the host. During the last years, probiotic bacteria proved to be beneficial not only for gut health as originally planned but also for oral health ${ }^{(10)}$. Probiotics compete with bacterial attachments resulting in biofilm formation that would act as a protective lining for oral tissues against oral diseases ${ }^{(11)}$. They secrete various antimicrobial substances such as organic acids, hydrogen peroxide and bacteriocins ${ }^{(12)}$. Furthermore, they have the potential to decrease plaque accumulation, reduce gingivitis and neutralize the acidic condition ${ }^{(13,14)}$. In addition, they proved to have a beneficial tendency on WSLs ${ }^{(15)}$. Therefore, they can be added to different commercial dairy products such as milk, cheese and yogurt as well as chewing gums and fruit drinks. Moreover, they can be delivered by vehicles such as lozenges, powder, gelatin, straw, or tablets ${ }^{(16)}$. Probiotics have a majority of strains and species, researchers concentrated essentially on lactobacillus acidophilus, Lactobacillus casei, Lactobacillus reuteri and bifdobacteriumbifidum while practically ignoring the vast array of other species ${ }^{(17)}$. Streptococcus rattus (S. rattus) is a very close relative of $S$. mutans but without lactic acid production which makes it unable to produce dental caries. Therefore, it is interesting to speculate that the two may compete with each other for binding sites; $S$. rattus could be used as a probiotic to reduce the level of S. mutans in plaque, and thereby promote dental health ${ }^{(18,19)}$. EvoraKids ${ }^{(20)}$ is the first probiotic blend, Streptococcus oralis (S oralis), Streptococcus uberis (S uberis) and S. rattus, made exclusively for a child's oral care that gently and safely promotes good oral health. Due to the availability of different types of probiotic strains with different delivery methods, further investigations are needed to assess their effect on the oral microflora. Considering the importance of oral heath, decrease in plaque accumulation and microbial count among children who are high caries risk should be of great interest through establishing self-performing antimicrobial plaque control measures as an adjunct to the mechanical measures ${ }^{(21,22)}$. This study was designed to evaluate the effect of chewable probiotic tablets on plaque accumulation and gingival inflammation, salivary $\mathrm{pH}$ and remineralization of WSLs in preschool children with high caries risk. The null hypothesis was that there is no difference in the clinical outcomes of the two study groups. 


\section{MATERIALS AND METHODS}

This study was a blind randomized controlled clinical trial, two-group parallel arms. It was setup and reported according to the CONSORT Statement ${ }^{(23)}$. Ethical approval was obtained by Dental Research Ethics Committee (\#IRB NO: 00010556 - IORG 0008839). All children included in the study were healthy with an age range of 3-5 years with full primary dentition. They were high caries risk patients with at least one white spot lesion (WSL) with ICDAS II ${ }^{(24)}$ score 1 or 2 , free from any systemic disease and cooperative according to Frankl rating (score 3 or 4 ). ${ }^{(25)}$ Children were excluded from the trial if they had history of professionally applied topical fluoride, or received any antibiotic two weeks before or during the study to avoid the interference with the colonization of probiotic bacteria ${ }^{(26)}$. Children who were under probiotic therapy two weeks prior the study were also excluded to avoid the possibility of probiotic accumulative effect, thus altering the results ${ }^{(27)}$.

\section{Study setting}

Children were selected from outpatient clinic of the Pediatric Dentistry and Dental Public Health Department, Faculty of Dentistry, Alexandria University.

\section{Sample size estimation}

A total sample of 40 children were required based on $5 \%$ alpha error, $80 \%$ study power and mean plaque index for Probiotic (0.24) and placebo (0.37) with pooled SD of $0.14^{(13)}$ using Gpower 3.0.10.

\section{Randomization}

Participants complying with the inclusion criteria were randomly assigned using a computergenerated list of random numbers to one of the two arms. Allocation was performed by a trial independent individual and the allocation ratio was intended to be equal. Forty patients were randomized into 2 groups with equal allocation ratio 1:1. Block randomization was applied with block size of $4{ }^{(28)}$.

\section{Allocation Concealment}

Each child included in the study was given a serial number that was used in the allocation. These numbers were written on identical sheets of paper with the group to which each child was allocated. The papers were placed in opaque envelopes carrying the respective names of the children. A trial independent personnel was assigned the role of keeping the envelopes and unfolding them only at the time of treatment.

\section{Grouping}

Group I (test group, $\mathrm{N}=20$ ): were given the chewable probiotic tablets after routine tooth brushing for a period of 2 weeks, and group II (control group, $\mathrm{N}=20$ ): performed only routine tooth brushing for a period of 2 weeks.

\section{Blinding}

The investigator and the participants were not blinded to the treatment type as each group has to be given different instructions according to their treatment protocol. Only the statistician was blinded to the intervention group. After analysis was completed, the randomization code was broken to reveal the allocation group.

\section{Patients' recruitment}

Children attending the outpatient clinic were examined using dental light reflector. Visual inspection of all surfaces for WSLs was undertaken, initially with wet surface and after 5 seconds of drying with gentle air stream ${ }^{(29)}$. Out of 80 screened patients, 40 children $(\mathrm{N}=40)$ met the inclusion criteria and were enrolled in the clinical trial after informing their parents about the study protocol and signing their informed consent. 


\section{Oral hygiene instructions}

Oral hygiene instructions and dietary guidance were carried out for all patients participated in the study. Each child participated in the study was given a new soft toothbrush (Oral B, Procter and Gamble, Ireland Ltd, Green Road, Newbridge, Co. Kildare Ireland) and fluoridated toothpaste (Crest, Procter and Gamble Strasse 1, 64521 Gross-Gerau, Germany) to be used during the whole study period. The horizontal tooth brushing scrub technique ${ }^{(30)}$ was demonstrated to all children and their parents in the Pediatric Dental Clinic using a magnified dental model. The parents were asked to place an amount of toothpaste equal to the size of a pea on the toothbrush and to brush their children's teeth for 1 minute twice daily for 2 weeks ${ }^{(31)}$. On the day of sampling, parents were instructed to refrain from brushing their children's teeth in the morning, eating or drinking (except water) at least two hours before sampling procedure ${ }^{(6)}$. Instructions were also given that other sources of fluoride (supplemental or other dental products) should be avoided during the study period $^{(32)}$.

\section{Intervention}

\section{First visit}

At baseline, participants were assessed for salivary $\mathrm{pH}$ using $\mathrm{pH}$ meter (Checker ${ }^{\circledR}$ Plus $\mathrm{pH}$ Tester, Hanna instruments, Italy). After cleaning all patient's teeth using prophylaxis brush without a paste, dental plaque index (PI) by Silness-Loe index (33) and gingival index (GI) by Loe and Silness ${ }^{(34)}$ were recorded. The amount of dental plaque and gingival condition were assessed on the four tooth surfaces (buccal, mesial, distal, lingual) of six index teeth and were given a score from 0-3 according to index's criteria. All patients had a baseline PI score 0 , scores for GI were recorded in the patient's score sheet. DIAGNOdent ${ }^{\mathrm{TM}}$ (Kavo, Biberach, Germany) examination for each lesion was performed using calibrated DIAGNOdent ${ }^{\mathrm{TM}}$ Laser fluorescence device with connected probe $\mathrm{B}$ for the smooth surfaces. Calibration was performed daily before its use by using the ceramic calibration disk provided by the manufacturer. Three measurements of each lesion were taken and averaged to give the final score which was written in patients' score sheets ${ }^{(29)}$. Intraexaminer reproducibility of the DIAGNOdent ${ }^{\mathrm{TM}}$ readings revealed excellent Intra Class Coefficient (ICC) of 0.92. All examinations were performed by a single trained examiner.

\section{Initial saliva sample}

Saliva samples were collected from all the participants at baseline. The unstimulated whole saliva was collected in the morning in small sterile glass tubes. Children were asked to sit in an upright relaxed position and spit in the tubes once a minute for 10 minutes ${ }^{(35)}$. The digital $\mathrm{pH}$ meter was recorded after approximately 10 seconds once the meter reading stabilized. Calibration of the $\mathrm{pH}$ meter was done before each use with usage of standard $\mathrm{pH}-4.0$ and $\mathrm{pH}-7.0$ buffer solutions ${ }^{(14)}$.

For group I (test group), after baseline evaluation, children were given the chewable probiotic tablets (EvoraKids, Oragenics USA; active ingredient is Probiora $3{ }^{\circledR}$, S uberis $\mathrm{KJ} 2$, S oralis $\mathrm{KJ} 3^{\mathrm{TM}}$, S rattus $\mathrm{JH} 145^{\mathrm{TM}}, 300$ million $\mathrm{CFU}$ ) and were asked to chew it immediately after tooth brushing. Children chewed the tablet until it dissolved in the mouth and then swallowed it. Children were asked to refrain from eating or drinking for 1 hour after chewing the probiotic tablet. Parents were instructed to give their children one tablet per day in the morning after breakfast and tooth brushing (36). Each parent was given a packet containing the remaining 13 tablets with guided instructions for their use during the whole study period.

For Group II (control group), children performed tooth brushing twice per day for a period of two weeks.

Parents were given a follow-up chart to be signed after each time giving their children EvoraKids (for group I) or after tooth brushing (for group II). 
The chart included data of children regarding the name, age, group and the serial number given to the child. The investigator followed all the children participating in the study on regular basis (two times per week) for motivation and patient's compliance.

\section{Second visit}

After two weeks, PI and GI for each patient were scored, DIAGNOdent ${ }^{\mathrm{TM}}$ readings of each lesion were recorded as mentioned before, and a second salivary sample from each child, for salivary $\mathrm{pH}$ assessment, was collected using the same previous procedure.

\section{Statistical analysis}

Data was analyzed using SPSS software (version 25). For between groups comparisons, independent $\mathrm{t}$ test was used. Comparisons between baseline and after intervention within each group was assessed using paired t test. Significance level was set at $P$ value 0.05 .

\section{RESULTS}

At baseline, 80 children were assessed for eligibility, 40 were excluded and 40 children (20 males, 20 females) were included in the study. All the participants have received the allocated intervention and no one has been lost during the follow-up period (Fig. 1). There was no significant difference between the two groups in terms of sex ratio $(P=0.059)$ or mean age $(P=0.435)$.

\section{Effect on dental plaque and gingival condition}

Regarding the PI, the mean PI for both groups were 0 at base line which denotes an entirely free tooth surface from a clinically detectable plaque. A significant increase in plaque accumulation in both groups was recorded after two weeks of intervention $(P<0.0001)$. However, the mean PI scores after using the probiotic chewable tablets was lower than those of the control group with statistically significant difference ( $P=0.019)$ (Fig. 2). For the GI, within group comparison, the test group showed a statistically significant decrease after two weeks of intervention $(P=0.037)$. While the control group did not show a statistically significant difference from baseline $(P=0.700)$. Between group comparison, baseline evaluation did not show a statistically significant difference $(\mathrm{P}=0.575)$. After two weeks of intervention, the mean GI was lower in the test group than the control group with statistically significant difference $(\mathrm{P}=0.048)$ (Fig. 2).

\section{Effect on salivary pH}

Within group comparison, the test group showed an increase in the mean $\mathrm{pH}$ value after two weeks of intervention but was not statistically significant when compared to the base line values $(P=$ 0.552). However, in the control group there was a statistically significant decrease in the mean $\mathrm{pH}$ values after two weeks of intervention $(\mathrm{P}=0.035)$. By comparing the two groups, at base line, there was no statistically significant difference $(P=0.727)$. While, after two weeks of intervention there was a statistically significant difference $(P=0.002)$. The test group showed a percent increase in the mean $\mathrm{pH}$ values by 1.82 (0.72), while the control group showed a percent decrease by $3.61(0.55)$ at the end of the study with statistically significant difference between the two groups $(\mathrm{P}<0.0001)$ (Table 1).

\section{Effect on lesions remineralization}

Within group comparison showed a significant decrease in the mean DIAGNOdent ${ }^{\mathrm{TM}}$ scores in the test group after two weeks of intervention $(\mathrm{P}=0.005)$. No statistically significant difference in the control group was recorded $(\mathrm{p}=0.218)$. By comparing the two groups, no statistically significant difference in the mean DIAGNOdent ${ }^{\mathrm{TM}}$ scores at baseline and after two weeks of intervention have been recorded ( $P=0.925, P=0.085$, respectively). After two weeks of intervention, the test group showed a statistically significant percent of reduction in the mean DIAGNOdent ${ }^{\mathrm{TM}}$ scores as compared to the control group $(P<0.0001)$ (Table 2$)$. 


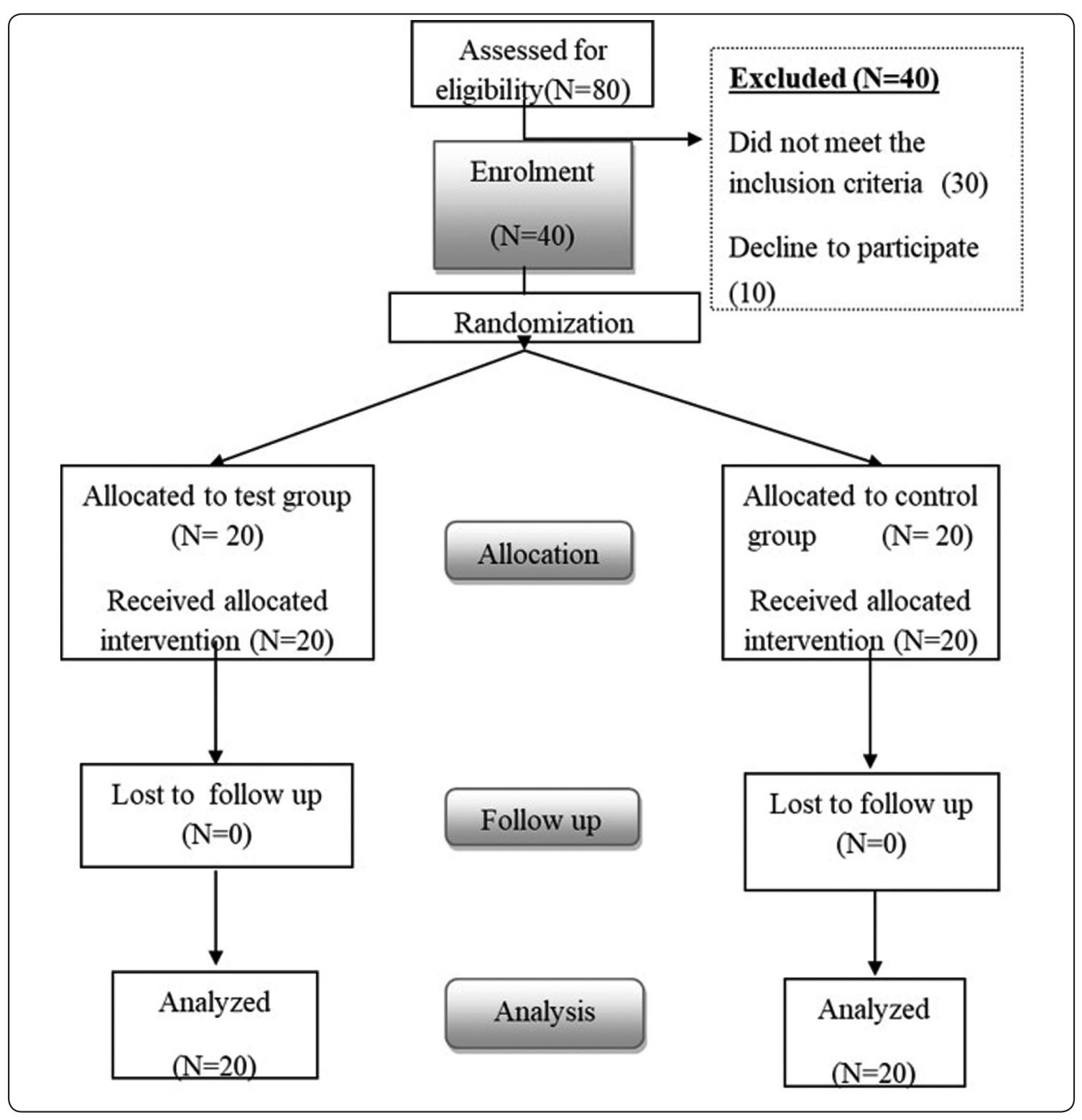

Fig. (1) A CONSORT diagram showing the study protocol.

TABLE (1): Comparison of the salivary mean $\mathrm{pH}$ between the test and control group at baseline and after 2 weeks of intervention.

\begin{tabular}{|c|c|c|c|c|}
\hline \multicolumn{2}{|c|}{} & Test $(\mathbf{N}=\mathbf{2 0})$ & Control $(\mathbf{N}=\mathbf{2 0})$ & \multirow{2}{*}{ P value } \\
\cline { 3 - 4 } \multicolumn{2}{|c|}{ Salivary PH } & Mean \pm SD & 0.727 \\
\cline { 2 - 4 } & After 2 weeks of intervention & $7.13 \pm 0.90$ & $7.21 \pm 0.48$ & $0.002^{*}$ \\
\hline \multicolumn{2}{|c|}{$\boldsymbol{P}$ value } & 0.552 & $6.95 \pm 0.23$ & \\
\hline \multicolumn{2}{|c|}{ Percent change Mean \pm SD } & $1.82(0.72)$ & $-3.61(0.55)$ & $<0.0001^{*}$ \\
\hline
\end{tabular}


TABLE (2): Comparison of the mean DIAGNOdent ${ }^{\mathrm{TM}}$ readings between the test and control group at baseline and after 2 weeks of intervention.

\begin{tabular}{|c|c|c|c|c|}
\hline & Test $(\mathrm{N}=20)$ & Control $(\mathrm{N}=20)$ & \multirow[t]{2}{*}{$P$ value } \\
\hline & & \multicolumn{2}{|c|}{ Mean \pm SD } & \\
\hline \multirow{2}{*}{$\begin{array}{l}\text { DIAGNOdent }{ }^{\mathrm{TM}} \\
\text { readings }\end{array}$} & At base line & $7.60 \pm 1.27$ & $7.56 \pm 1.40$ & 0.925 \\
\hline & After 2 weeks of intervention & $6.30 \pm 1.50$ & $7.05 \pm 1.17$ & 0.085 \\
\hline \multicolumn{2}{|r|}{$P$ value } & $0.005^{*}$ & 0.218 & \\
\hline \multicolumn{2}{|c|}{ Percent reduction Mean \pm SD } & $17.11(1.13)$ & $6.74(1.20)$ & $<0.0001 *$ \\
\hline
\end{tabular}

*Statistically significant different at $P$ value $\leq 0.05$

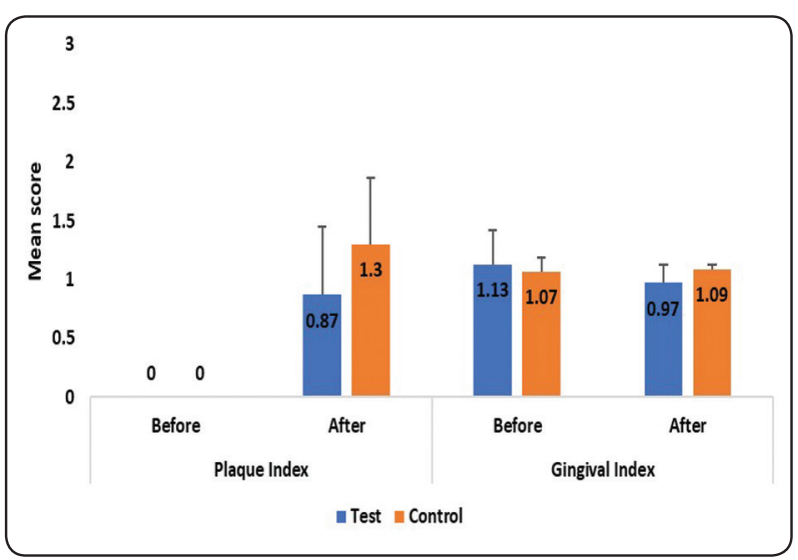

Fig. (2): Mean score and error bars of the plaque index and gingival index between the test and control groups at baseline and after 2 weeks of intervention.

\section{DISCUSSION}

In an attempt to stop the carious process overtime, attention should be directed toward enhancement of the remineralization of tooth structure through maintaining a favorable oral environment ${ }^{(37)}$. Bacteriotherapy is an approach used to maintain oral health by using harmless bacteria to displace pathogenic microorganisms thought to be harmful to teeth and gum ${ }^{(38)}$. Long-term effect could be achieved through early installation and colonization of probiotics in the oral environment ${ }^{(22)}$.

Therefore, this study aimed to evaluate the effect of chewable probiotic tablets on plaque accumulation and gingival inflammation, salivary $\mathrm{pH}$ and remineralization of WSLs in pre-school children with high caries risk.
This study was dependent on child compliance so all the children selected in this study had to be cooperative (positive or definitely positive) according to Frankl Behavior Rating Scale (25) to ensure their regular attendance to scheduled appointments and the punctual intake of the probiotic tablets. Evorakids chewable tablets were chosen as a vehicle for administration of the probiotics as they are especially designed as a caries preventive method for children ranging from 3-10 years and are approved by the FDA ${ }^{(20)}$.

By comparing the PI in the two study groups, results revealed that the rate of plaque accumulation after two weeks of using the probiotic was less than the mechanical conventional oral hygiene procedure with a statistically significant difference. This endorses the fact that the probiotic can be considered as an antiplaque agent. This antiplaque effect could be achieved in different ways, these include the interference with bacterial adhesion to the tooth surface, inhibition of bacterial growth and proliferation on tooth surface, inhibition of intercellular plaque matrix formation and plaque ecology modification to less pathogenies flora ${ }^{(39)}$. The two strains of ProBiora3, S. uberis and S. Oralis, are known to produce hydrogen peroxide so they are considered effective in inhibiting the growth of periodontal pathogens ${ }^{(18)}$. Similarly, GI showed a notable difference between the two study groups in favor of the test group. As plaque is the etiological agent for gingivitis so using a therapeutic agent that is able to make plaque control will be by its turn able to 
demonstrate a significant effect against gingivitis ${ }^{(40)}$. These results go in line with several studies ${ }^{(13,22,38,41}$ ${ }^{42,43)}$. In contrast, Alkaya et al ${ }^{(44)}$ did not report a significant difference in the gingival or plaque indices between the probiotic and placebo group. Similarly, Angarita-Díaz et al ${ }^{(45)}$ and Villavicencio et al ${ }^{(46)}$ did not show a significant effect on plaque index after consuming milk with probiotics. Additionally, the outcome of the systematic review conducted by Keukenmeester et al ${ }^{(47)}$ and Akram et al ${ }^{(48)}$ showed a weak evidence to support the use of probiotics in reducing inflammatory parameters in gingivitis. This variation between the studies could be due to the use of different probiotic strains and different vehicles of administration.

Regarding the salivary $\mathrm{pH}$, within group comparison, results revealed increase in the $\mathrm{pH}$ readings in the test group providing a suitable environment for tooth remineralization. However, the control group showed a notable decrease in the salivary $\mathrm{pH}$ which is responsible for the initiation or progression of dental caries ${ }^{(14)}$. This result goes in line with Hoorizad et al ${ }^{(49)}$ and Srivastava ${ }^{(14)}$. However, they noted a significant increase in the probiotic group as the use of probiotic into dairy products play a role to neutralize the acidic conditions in the mouth ${ }^{(14)}$. On the contrary, Angarita-Díaz et al ${ }^{(45)}$ showed a significant decrease in the salivary $\mathrm{pH}$ in the probiotic group. This contradiction could be due to the use of acidogenic probiotics as Lactobacillus rhamnosus species in their study which demonstrated to have the ability to produce acids ${ }^{(50)}$. Similarly, Sudhir et al ${ }^{(51)}$ showed a notable reduction in the $\mathrm{pH}$ after 30 days of probiotic consumption.

For monitoring the carious process, the high level of agreement for a laser fluorescence device renders it useful for early mineral loss and gain quantification (52). The high sensitivity and acceptable specificity of DIAGNOdent ${ }^{\mathrm{TM}}$ made it useful for monitoring the progression of smooth surface carious lesions ${ }^{(53)}$. DIAGNOdent ${ }^{\mathrm{TM}}$ scores range from 0-99, change in lesion scores denotes a change in mineralization status of the lesion as increase in the score, due to more fluorescence, is a sign of demineralization while its decrease indicates remineralization ${ }^{(29)}$.

From the present study, within group comparison showed a significant decrease in the DIAGNOdent ${ }^{\mathrm{TM}}$ readings after two weeks of using the probiotic, however the decrease in the control group was not notable. Therefore, probiotic can act in concert with fluoride for the prevention of caries in pre-school children. This result goes in line with Gokce et al ${ }^{(54)}$ and Keller et al ${ }^{(15)}$ who showed the beneficial effect of probiotics in the control of WSLs. By comparing the two groups, no statistically significant difference was noted before or after two weeks of intervention. Keller et al ${ }^{(15)}$ was in agreement with this result. However, Angarita-Díaz et al ${ }^{(45)}$ found that the percentage of carious lesions remineralization was significantly higher following the administration of no probiotic milk than milk with probiotic. This contradiction from the results of the present study could be due to the use of different bacterial strain or different vehicle for probiotic administration.

In the present study, probiotic chewable tablets proved to have a beneficial effect in decreasing the plaque accumulation, improving the gingival condition, prevent the reduction of the salivary $\mathrm{pH}$ and showed a remineralizing tendency of the WSLs. On the other hand, brushing twice daily with fluoridated tooth paste was not sufficient enough to decrease the plaque accumulation, improve gingival condition, increase salivary $\mathrm{pH}$ and remineralize the early enamel lesions in high caries risk children.

A possible limitation of the present study was that once the probiotic bacteria have colonized the oral cavity, they could exert a better clinical effect that did not show during the short-term intervention. Moreover, the post treatment effect of using the chewable probiotic tables was not proved by the current study. Within the limitations of this study and based on the previous data, the hypothesis that there is no difference in the clinical outcomes of the two study groups was partially rejected. 


\section{CONCLUSIONS}

A short term daily intake of probiotic chewable tablets was notably effective to decrease the rate of plaque accumulation and decrease the gingival index as compared to the control group. Moreover, it increased the salivary $\mathrm{pH}$ significantly as compared to the control group and decreased the DIAGNOdent ${ }^{\mathrm{TM}}$ readings which denotes remineralization of the WSLs. Therefore, probiotics play an important role in the improvement of oral health. Additionally, they can be used as an adjunct to fluoride in dental caries prevention or control in high caries risk children.

\section{REFERENCES}

1. Selwitz RH, Ismail AI, Pitts NB. Dental caries. J Lancet 2007;6:51-9.

2. American Academy of Pediatric Dentistry. Guideline on caries-risk assessment and management for infants, children, and adolescents, 2019. The Reference Manual of Pediatric Dentistry. Chicago, III.: American Academy of Pediatric Dentistry; 2019: 243-7.

3. Carounanidy U, Sathyanarayanan R. Dental caries: A complete changeover, PART III: Changeover in the treatment decisions and treatments. Carounanidy U, Sathyanarayanan R. Dental caries: A complete changeover, PART III: Changeover in the treatment decisions and treatments. J Conserv Dent. 2010;13: 209-17.

4. Vadiakas G. Case definition, aetiology and risk assessment of early childhood caries (ECC): A revisited review. European Arch Paed Dent 2008; 9:114-25.

5. Tsang P, Qi F, Shi W. Medical approach to dental caries: Fight the disease, not the lesion. Pediatr Dent 2006; 28:188-98.

6. Li J, Helmerhorst EJ, Leone CW, Troxler RF, Yaskell $\mathrm{T}$, Haffajee $\mathrm{AD}$, et al. Identification of early microbial colonizers in human dental biofilm. J Appl Microbiol. 2004; 97:1311-18.

7. Caglar E, Kavaloglu SC, Kuscu OO, Sandalli N, Holgerson PL, Twetman S. Effect of chewing gums containing xylitol or probiotic bacteria on salivary mutans streptococci and lactobacilli. J Clin Oral Investig 2007; 11: 425-9.

8. Zero DT. Dentifrices, mouthwashes, and remineralization/ caries arrestment strategies. In BMC Oral health 2006; 6:1-13. BioMed Central.
9. Food and Agriculture Organization and World Health Organization Expert Consultation. Evaluation of health and nutritional properties of powder milk and live lactic acid bacteria. 2001. Available at: http://www.who.int/ foodsafety/fs_management/en/probiotic_guidelines.pdf

10. Haukioja A. Probiotics and Oral Health. Eur J Dent 2010; 4: 348-55.

11. Jain P, Sharma P. Probiotics and their efficacy in improving oral health: A review. JAPS 2012;2: 151-63.

12. Bonifait L, Chandad F, Grenier D. Probiotics for Oral Health: Myth or Reality? J Can Dent Assoc 2009; 75: 585-90.

13. Noordin K, Kamin S. The Effect of probiotic mouthrinse on plaque and gingival inflammation. Annals Dent Univ Malaya. 2007; 14:19-25.

14. Srivastava S, Saha S, Minti Kumari SM. Effect of probiotic curd on salivary $\mathrm{pH}$ and Streptococcus mutans: a double blind parallel randomized controlled trial. J Clin Diagn Res. 2016;10: ZC13-ZC16.

15. Keller MK, Nøhr Larsen I, Karlsson I, Twetman S. Effect of tablets containing probiotic bacteria (Lactobacillus reuteri) on early caries lesions in adolescents: a pilot study. Benef Microbes. 2014; 5:403-7.

16. Caglar E, Cildir SK, Ergeneli S, Sandalli N, Twetman S. Salivary mutans streptococci and lactobacilli levels after ingestion of the probiotic bacterium Lactobacillus reuteri ATCC 55730 by straws or tablets. J Acta Odontol Scand 2006; 64: 314-8.

17. Choudhari S, Mopgar V, Sakhare S, Patil N. Probiotic way of dental caries prevention. Int J Contemp Dent 2011; 2:59-64.

18. Zahradnik RT, Magnusson I, Walker C, McDonell E, Hillman $\mathrm{CH}$, Hillman JD. Preliminary assessment of safety and effectiveness in humans of ProBiora3, a probiotic mouthwash. J Appl Microbiol 2009; 107: 682-90.

19. Hillman JD, McDonell E, Cramm T, Hillman CH, Zahradnik RT. A spontaneous lactate dehydrogenase deficient mutant of Streptococcus rattus for use as a probiotic in the prevention of dental caries. J Appl Microbiol.b 2009; 107:1551-8

20. DentistryIQ, 2010. Probiotic oral-care system for kids launched: EvoraKids' ProBiora3 blend of probiotics fights harmful oral bacteria and helps maintain tooth health. [Online] Available at: https://www.dentistryiq.com/dentistry/ products/article/16372387/probiotic-oralcare-system-forkids-launched [Accessed 6 February 2021]. 
21. Kidd EA. Role of chlorhexidine in the management of dental caries. Int Dent J 1991; 41: 279-86.

22. Harini PM, Anegundi RT. Efficacy of a probiotic and chlorhexidine mouth rinses: A short-term clinical study. J Indian Soc Pedod Prev Dent. 2010; 28:179-82.

23. Schulz KF, Altman DG, Moher D. CONSORT 2010 Statement: updated guidelines for reporting parallel group randomised trials. BMC Med 2010; 8:18.

24. Ismail AI, Sohn W, Tellez M, Amaya A, Sen A, Hasson $\mathrm{H}$, et al. The International Caries Detection and Assessment System (ICDAS): an integrated system for measuring dental caries. Community Dent Oral Epidemiol 2007; $35: 170-8$.

25. Frankl SN, Shire FR FH. Should the parent remain with the child in the dental operatory? J Dent Child 1962; 29:150-63.

26. Yli-Knuuttila H, Snäll J, Kari K, Meurman JH. Colonization of Lactobacillus rhamnosus GG in the oral cavity. Oral Microbiol Immunol 2006; 21:129-31.

27. Glavina D, Gorseta K, Skrinjaric I, Vranic ND, Mehulic K, Kozul K. Effect of LGG Yoghurt on Streptococcus Mutans and Lactobacillus Spp. Salivary Counts in Children. Coll Antropol 2012; 36: 129-32.

28. Saghaei M. Random allocation software for parallel group randomized trials. BMC Med Res Methodol. 2004; 4:1-6.

29. Llena C, Leyda AM, Forner L. CPP-ACP and CPP-ACFP versus fluoride varnish in remineralisation of early caries lesions. A prospective study. Eur J Paediatr Dent 2015; 16:181-6.

30. Dean JA and Hughes CV. Mechanical and Chemotherapeutic Home Oral Hygiene In: McDonald RE, Avery DR, Dean JA, eds. Dentistry for the Child and Adolescent. $9^{\text {th }}$ ed. USA: Mosby, 2011. 205-21.

31. American Academy of Pediatric Dentistry. Policy on early childhood caries (ECC): Classifications, consequences, and preventive strategies. The Reference Manual of Pediatric Dentistry. Chicago, Ill.: American Academy of Pediatric Dentistry 2020; 79-81.

32. American Academy of Pediatric Dentistry. Guideline on fluoride therapy,2018. Reference Manual of Pediatric Dentistry. Chicago, III.: American Academy of Pediatric Dentistry 2019: 262-5.

33. Silness J, Loe H. Periodontal disease in pregnancy. II. Correlation between oral hygiene and periodontal condition. Acta OdontolScand 1964; 24: 747-59.
34. Loe H, Silness J. Periodontal disease in pregnancy. I. Prevalence and severity. Acta Odontol Scand 1963; 21:533-51.

35. Sudhir R, Praveen P, Anantharaj A, Venkataraghavan K. Assessment of the effect of probiotic curd consumption on salivary $\mathrm{pH}$ and streptococcus mutans counts. Niger Med J 2012; 53:135-9.

36. Hedayati-Hajikand T, Lundberg U, Eldh C, Twetman S. Effect of probiotic chewing tablets on early childhood caries-a randomized controlled trial. BMC oral health 2015; $15: 1-5$.

37. Haaukioja A, Loimaranta V, Tenovuo J. Probiotic bacteria affect the composition of salivary pellicle and streptococcal adhesion in vitro. Oral Microbiol Immunol 2008; 23:336-43.

38. Dhawan R, Dhawan S. Role of probiotics on oral health: A randomized, double-blind, placebo-controlled study. J Interdiscip Dent 2013; 3:71-8.

39. Cummins \& Creeth JE. Delivery of Antiplaque agents from dentrifices, gel and mouthwashes. J Dent Res 1992; 7: 1439-49.

40. Wu CD, Savitt ED. Evaluation of the safety and efficacy of the over-the-counter oral hygiene products for the reduction and control of plaque and gingivitis. Periodontology 2000 2002; 28: 91- 105.

41. Kuru BE, Laleman I, Yalnızoğlu T, Kuru L, Teughels W. The Influence of a Bifidobacterium animalis Probiotic on Gingival Health: A Randomized Controlled Clinical Trial. J Periodontol 2017; 88:1115-23.

42. Kaur K, Nekkanti S, Madiyal M, Choudhary P. Effect of chewing gums containing probiotics and xylitol on oral health in children: a randomized controlled trial. J Int Oral Health 2018; 10:237-43.

43. Vivekananda MR, Vandana KL, Bhat KG. Effect of the probiotic Lactobacilli reuteri (Prodentis) in the management of periodontal disease: a preliminary randomized clinical trial. J Oral Microbiol. 2010; 2:5344.

44. Alkaya B, Laleman I, Keceli S, Ozcelik O, Cenk Haytac M, Teughels W. Clinical effects of probiotics containing Bacillus species on gingivitis: a pilot randomized controlled trial. J Periodontal Res. 2017; 52:497-504.

45. Angarita-Díaz MP, Forero-Escobar D, Cerón-Bastidas XA, Cisneros-Hidalgo CA, Dávila-Narvaez F, BedoyaCorrea CM, et al. Effects of a functional food supplemented with probiotics on biological factors related to dental 
caries in children: a pilot study. Eur Arch Paediatr Dent. 2020; 21:161-9.

46. Villavicencio J, Villegas LM, Arango MC, Arias S, Triana F. Effects of a food enriched with probiotics on Streptococcus mutans and Lactobacillus spp. salivary counts in preschool children: a cluster randomized trial. J Appl Oral Sci. 2018;26: e20170318.

47. Keukenmeester RS, Slot DE, Putt MS, Van der Weijden GA. The effect of medicated, sugar-free chewing gum on plaque and clinical parameters of gingival inflammation: a systematic review. Int J Dent Hyg. 2014; 12:2-16.

48. Akram Z, Shafqat SS, Aati S, Kujan O, Fawzy A. Clinical efficacy of probiotics in the treatment of gingivitis: A systematic review and meta-analysis. Aust Dent J. 2020; 65:12-20.

49. Hoorizad M, Mirhashemi M, Rahpeyma R, Salehi M, Zavareian S. Effect of probiotic yoghurt on the salivary $\mathrm{pH}$ of orthodontic patients- A clinical trial study. J Res Dent Sci $2013 ; 10: 155-59$.
50. Schwendicke F, Dörfer C, Kneist S, Meyer-Lueckel H, Paris S. Cariogenic effects of probiotic Lactobacillus rhamnosus GG in a dental biofilm model. Caries Res 2014; 48:186-92.

51. Sudhir R, Praveen P, Anantharaj A, Venkataraghavan K. Assessment of the effect of probiotic curd consumption on salivary $\mathrm{pH}$ and streptococcus mutans counts. Niger Med J. 2012; 53:135-9.

52. Lussi A, Hellwig E. Performance of a new laser fluorescence device for the detection of occlusal caries in vitro. $\mathrm{J}$ Dent 2006; 34:467-71.

53. Moriyama CM, Rodrigues JA, Lussi A, Diniz MB. Effectiveness of fluorescence-based methods to detect in situ demineralization and remineralization on smooth surfaces. Caries Res. 2014; 48:507-14.

54. Gokce G, Savas S, Kucukyilmaz E, Veli I. Effects of toothpastes on white spot lesions around orthodontic brackets using quantitative light-induced fluorescence (QLF): An in vitro study. J Orofac Orthop 2017; 78:480-6. 